\title{
Assessment of Types and Abundance of Live Food for Fish Farming in Makoba Earthen Ponds, Zanzibar, Tanzania
}

\author{
Margareth S. Kyewalyanga \\ Institute of Marine Sciences, University of Dar es Salaam, P. O. Box 668, Zanzibar, Tanzania
}

Key words: live food, rotifers, protozoa, phytoplankton, fertilisation, earthen ponds

\begin{abstract}
Surveys of naturally-occurring live food for fish in Makoba earthen ponds, Zanzibar were conducted from November 2001 to August 2002. This involved identification of dominant plankton in the water column as well as the composition of algal mats. The effect of nutrients on the composition and abundance of the organisms was also assessed. Protozoa were found to be the dominant zooplankton in the water column, followed by rotifers. The most abundant phytoplankton genera were Prorocentrum (13.4\%), followed by Coscinodiscus (10.4\%) and Diplopsalopsis (7.5\%), while the benthic algal mats were dominated by cyanobacteria, mostly Spirulina (22\%) and Oscillatoria (18.4\%).

To complement the surveys, a time-series experiment was conducted for 21 consecutive days to assess the dynamics of plankton in earthen ponds and simulation containers, using a fertilisation rate of $83 \mathrm{~kg}$ dry matter/ha/day. Protozoa were the most dominant zooplankton in the earthen ponds. Fertilisation with chicken manure was effective in increasing the number of rotifers in simulation containers, but not in the earthen ponds; this was probably because, unlike the earthen ponds, the simulation containers were sheltered from external influences such as rain, flooding by tide water, etc. The phytoplankton genera Pyramimonas (16.7\%), Biddulphia and Microcystis (8.3\%) dominated the fertilised ponds. Chlorophyll- $a$ concentration ranged from 1.8 to $16.9 \mathrm{mg} / \mathrm{l}$, whereas soluble reactive phosphorous (SRP) and ammonia-N reached maximum concentrations of $1.4 \mu \mathrm{g}$-at.P/l and $9.7 \mu \mathrm{g}$-at.N/l respectively. Overall, salinity and fertilisation played a major role in controlling the abundance of live/natural food in the system.
\end{abstract}

\section{INTRODUCTION}

Food availability is one of the most important biotic factors affecting the success of fish culture. However, the type and nature of the food is also of paramount importance to any aquaculture operation. In mariculture, plankton appears to have the highest potential, and mass-cultured zooplankton, particularly rotifers and artemia, have been often used as food (Schluter \& Groeneweg, 1985; Estudillo et al., 1998). Nevertheless, plankton density, composition and succession patterns can greatly affect fish production at the earliest stage of their life (Parmley \& Geiger, 1985, Harrell and Bukowski, 1990). Natural food supplies a considerable part of the protein and other nutrients required by fish, thus reducing the demand for supplementary nutrients (Milstein et al., 1985; Fengqi, 1996). It thus reduces the total cost of production, since supplements can be expensive.

Preliminary studies conducted between 1999 and 2001 at Makoba, Zanzibar have revealed that fertilisation of earthen ponds using chicken manure, while maintaining low salinities (between 20-30\%o) could provide optimal conditions for the production of various live food types, especially rotifers, for fry and fingerlings (Kyewalyanga \& Mwandya, 2002; Kyewalyanga et al., unpublished data). As a follow-up, the present study aims at (i) assessing variation in types and abundance of live 
food with time and the role played by environmental variables, particularly nutrients; (ii) examining the importance of fertilisation (with chicken manure) in increasing the quantity of the food; and (iii) comparing outcomes from simulation containers with those from natural ponds. The results obtained are discussed in light of their usefulness in establishing and maintaining fish nurseries, under mesocosm conditions.

\section{MATERIALS AND METHODS}

\section{Study area}

The study was conducted between November 2001 and August 2002 at Makoba, a mangrove area located some $20 \mathrm{~km}$ from Zanzibar town, on the north west side of Unguja Island. The study site was originally used for salt production. The whole

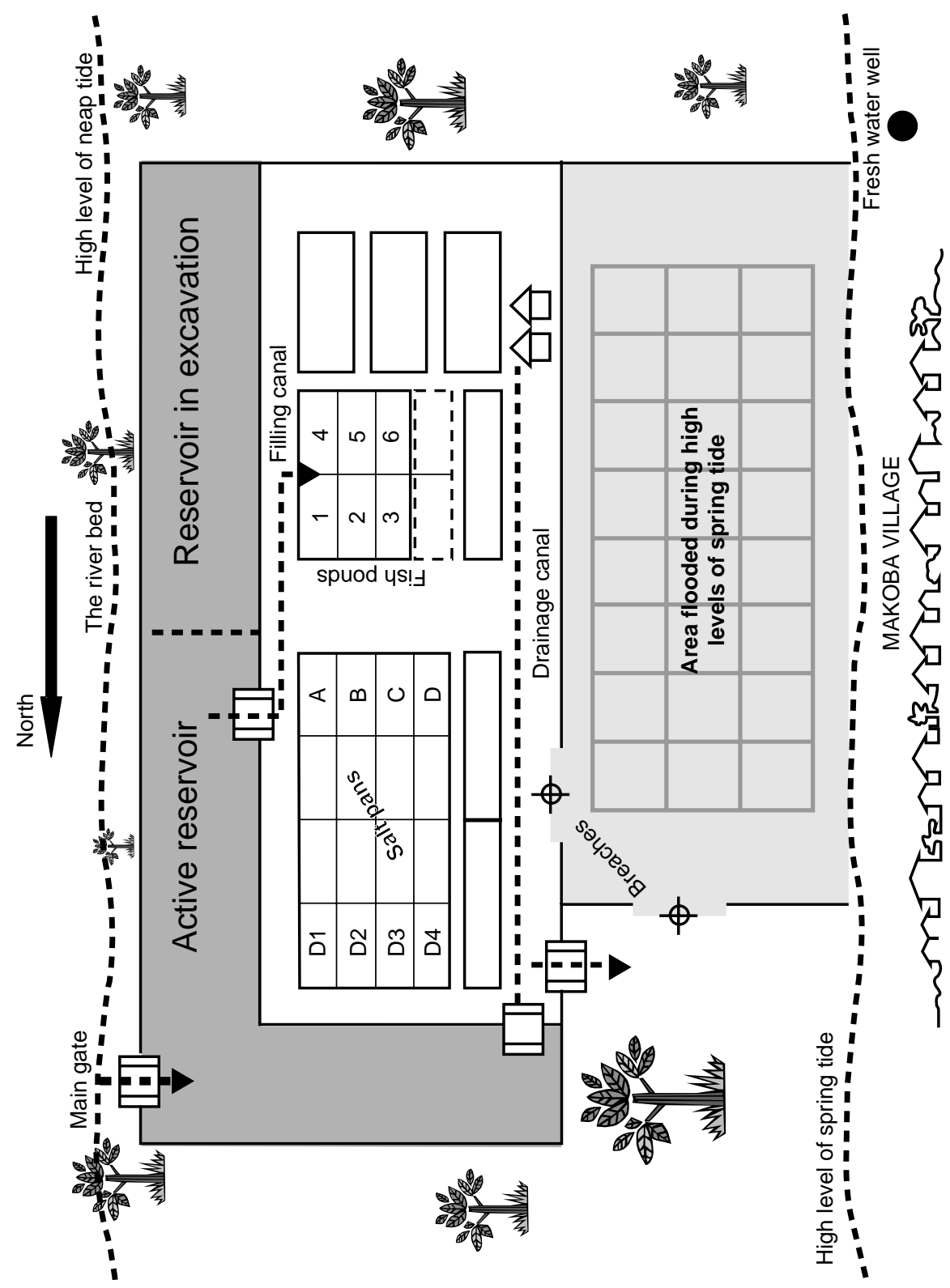


area (ca 15 ha) is separated from the mangroves by earthen walls. It is confined to a zone limited between high level of neap tide and high level of spring tide. The main components include several small, shallow, ponds and an operational reservoir that covers about one-third of the total area (Fig. 1).

\section{Monitoring of plankton and environmental variables}

Direct measurements of abiotic variables and collection of water samples for laboratory analyses were made in the reservoir $(\mathrm{R})$, as a control, and in three different un-manipulated earthen ponds. These ponds were named as $\mathrm{P} 1, \mathrm{P} 2$ and $\mathrm{P} 3$. The choice of these ponds was random, to obtain unbiased representation of the measured variables as well as abundance and types of both planktonic and benthic live food for fish at Makoba. The size of ponds was approximately $15 \times 12 \mathrm{~m}$ each and they were shallow-about $0.25 \mathrm{~m}$ in depth. Algal mats often covered the bottom layers. Water samples were collected from different points in the ponds, mixed in one container, and a sub-sample was then taken from the mixture. Planktonic samples were not fixed since identification and counting was done immediately after returning to the laboratory.

The water column was surveyed weekly for phytoplankton, phytobenthos, zooplankton as well as abiotic variables. Phytoplankton were identified up to the genus level. Throughout the 10-month survey, the frequency of occurrence of the genera found was calculated as the percentage composition of the total number of genera.

Phytoplankton and phytobenthos (Bryceson, 1977; Sundström, 1986; Lugomela, 1996) were identified in the laboratory using a light microscope, while zooplankton were counted and identified under a dissecting microscope, using a custom-made counting chamber. No counting of phytoplankton or phytobenthos was performed, except that the frequency of occurrence for each genus was estimated as percentage of the total number of the observed genera. Temperature, oxygen concentration and oxygen saturation were measured in situ using an oxygen meter (OxyGuard). Salinity was estimated using a hand refractometer. The $\mathrm{pH}$ of the water and conductivity were directly measured using a portable pH meter (Hanna Instrument: HI 8014).

\section{Experiments in fertilised earthen ponds and simulation containers}

A time-series fertilisation experiment was conducted for 21 consecutive days in January 2002 with the main objective of assessing how fertilisation could influence or affect natural succession and abundance of the plankton in the ponds. The trials were made in three earthen ponds, having similar size and characteristics as those chosen for the survey. One pond (PA) was not fertilised-this served as a control. The remaining two ponds (PB and PC) were fertilised with chicken manure at a rate of $83 \mathrm{~kg}$ dry matter/ha/ day. Ponds PB and PC were flooded with reservoir waters, which passed via PA. The reservoir was the standard/control and a source of seawater. The reservoir receives seawater every high spring tide, that is, about once a fortnight. To maintain the salinity similar to that of the reservoir, flooding of the ponds was done frequently, at least once every 2-3 days. Data collected from these experimental ponds was the same as those collected in the survey ponds. However, additional measurements were made here, including estimation of phytoplankton biomass as chlorophyll-a concentration, determined using a Shimadzu UV-1201 spectrophotometer. Further, the concentrations of soluble reactive phosphates and ammonia- $\mathrm{N}$ were measured using the automated phenate method (Parsons et al., 1984).

During the 21 days of the experiment, fertilisation trials were carried out in plastic containers, as simulations. The necessity of these simulations was to provide more controlled environment under which to assess the dynamics of live food. There were three simulations: two treatments and one control, to mimic the pond situation. However, every treatment had two replicates, giving a total of 6 containers. Five litres of sediments, collected from the upper $3-4 \mathrm{~cm}$ surface of salt ponds fringes were placed in each experimental container, with a capacity of 30 litres. The containers were filled with seawater from each of the respective ponds, and no prior filtration was made to remove existing plankton. The containers 
Table 1. Summary of treatments used in the 21-day time series experiment at Makoba ponds

\begin{tabular}{ll}
\hline Pond experiments & Simulation (container) experiment \\
\hline Pond A: Control. Flooded but not fertilised. & A1 and A2: control replicates, no fertilisation with chicken \\
Located close to Reservoir & manure \\
Pond B: Flooded and fertilised with 3 litres chicken & $\begin{array}{l}\text { B1 and B2: simulating Pond B; fertilised with } 20 \mathrm{ml} \text { of } \\
\text { chicken manure }\end{array}$ \\
manure. Located next to Pond A & $\begin{array}{l}\text { C1 and C2: simulating Pond C; also fertilised with } 20 \mathrm{ml} \text { of } \\
\text { chicken manure }\end{array}$ \\
Pond C: Flooded and fertilised as in PB. & Located next to Pond B, in series.
\end{tabular}

were then immersed almost three quarters in Pond A. Fertilisation rate in the containers was $20 \mathrm{ml}$ fry matter per 30-1 container per day (A. Valdenberg, pers. commun.). Given the size of the ponds (area and depth) the rate of $20 \mathrm{ml}$ manure per container was assumed to bring about similar strengths as the rate applied in the earthen ponds. Table 1 summarises the treatments for both setups, i.e., the ponds and the containers.

\section{Data analysis}

To assess differences in the biotic or abiotic variables in the treatments for survey ponds, fertilised ponds and simulation containers, oneway ANOVA (analysis of variance) was used. In cases where significant differences were detected at $\mathrm{P}<0.05$, the ANOVA was followed by a Post- hoc comparison of means-Tukey honest significance difference (HSD) test-applied to determine which means were actually different (Table 2).

\section{RESULTS AND DISCUSSION}

\section{Dynamics of phytoplankton and zooplankton}

Prorocentrum sp. was the dominant genus in the water column, with an occurrence of $13 \%$. Coscinodiscus sp. was the second-most abundant, at about $10 \%$ (Fig. 2a). Other commonly occurring genera included Diplopsalopsis sp., Gyrodinium sp., Protoperidinium sp. and Ostreopsis sp. A total of about 24 less-abundant genera constituted 50\% of total occurrence (Fig. 2a).

Table 2. Mean biotic or abiotic variables (standard error in parentheses) for three fertilised ponds, three simulation containers and three survey/ natural ponds. ANOVA was used to test for significant differences, followed by Tukey's means comparison test

\begin{tabular}{|c|c|c|c|}
\hline \multicolumn{4}{|l|}{ Variable } \\
\hline & \multicolumn{3}{|c|}{ Fertilised ponds } \\
\hline & $\mathrm{PA}^{+}$ & PB & $\mathrm{PC}$ \\
\hline Chlorophyll- $a(\mu \mathrm{g} / 1)$ & $2.81(0.51) \mathrm{a}$ & $5.78(1.01) b$ & $2.97(0.46) \mathrm{a}$ \\
\hline Rotifers (No./ml) & $5.12(0.92) \mathrm{a}$ & $10.64(1.72) b$ & $9.22(1.42) \mathrm{a}, \mathrm{b}$ \\
\hline \multirow[t]{3}{*}{ Protozoa (No./ml) } & $7.29(1.01) \mathrm{a}$ & $13.93(2.66) \mathrm{a}$ & $10.43(1.81) \mathrm{a}$ \\
\hline & \multicolumn{3}{|c|}{ Simulation containers } \\
\hline & $\mathrm{A} 1^{+}$ & B1 & $\mathrm{C} 1$ \\
\hline Rotifers (No./ml) & 7.57 (1.61)a & $69.79(14.22) \mathrm{b}$ & $54.09(11.38) \mathrm{c}$ \\
\hline \multirow[t]{3}{*}{ Protozoa (No./ml) } & $12.75(1.96) \mathrm{a}$ & $22.22(6.46) b$ & $14.55(1.25) \mathrm{c}$ \\
\hline & \multicolumn{3}{|c|}{ Natural survey ponds } \\
\hline & $\mathrm{P} 1$ & $\mathrm{P} 2$ & P3 \\
\hline Rotifers (No./ml) & $3.95(0.94) \mathrm{a}$ & $4.67(1.01) \mathrm{a}$ & $4.49(0.54) \mathrm{a}$ \\
\hline Protozoa (No./ml) & $10.31(1.27) \mathrm{a}$ & 10.89 (1.79)a & $10.27(1.08) \mathrm{a}$ \\
\hline
\end{tabular}

${ }^{+}$Control; Means followed by different lowercase letters are significantly different at $\mathrm{P}<0.05$. 

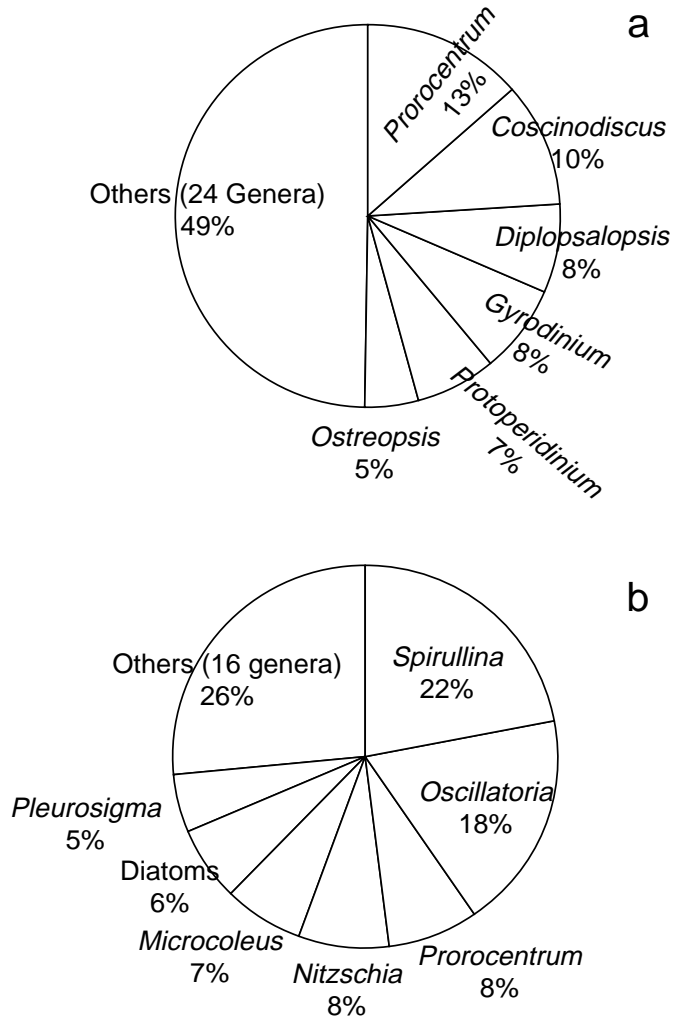

Fig. 2. Percentage abundance of (a) phytoplankton genera and (b) benthic algal mats at Makoba ponds, Zanzibar during November 2001 to August 2002
For the benthic algae (algal mats), Spirulina sp. was the most dominant among the phytobenthos (22\%), followed by Oscillatoria sp. (18\%), Nitzschia sp. and Prorocentrum sp. (8\% each; Fig. 2b). Others were Pleurosigma sp., Microcoleus sp. and unidentified diatoms (occupying between 5 and $7 \%$ ). Sixteen other unidentified genera accounted for $26 \%$ of the total (Fig. 2b).

The abundance of phytoplankton was estimated using chlorophyll- $a$ concentration, which was determined only during the second and third weeks of the time-series experiment. The ANOVA showed that the concentration of chlorophyll was significantly different between PA, PB and PC, at $P<0.05$. Tukey's HSD (Table 2) further revealed that the chlorophyll- $a$ concentration in Pond B was significantly higher than that in Pond $\mathrm{A}(\mathrm{P}=0.013)$ and Pond $\mathrm{C}(\mathrm{P}=0.019)$, although Pond $\mathrm{C}$ was also fertilised. For time-series variation, the difference between fertilised and unfertilised ponds was not large in the second week. However, during the third week the difference increased (Fig. 3).

Chlorophyll- $a$ concentration ranged from a minimum of 0.2 (in the control pond) to a maximum of $16.9 \mu \mathrm{g} / \mathrm{l}$ in fertilised Pond B. It should be noted that the ponds are naturally relatively fertile and they often contain a carpet of

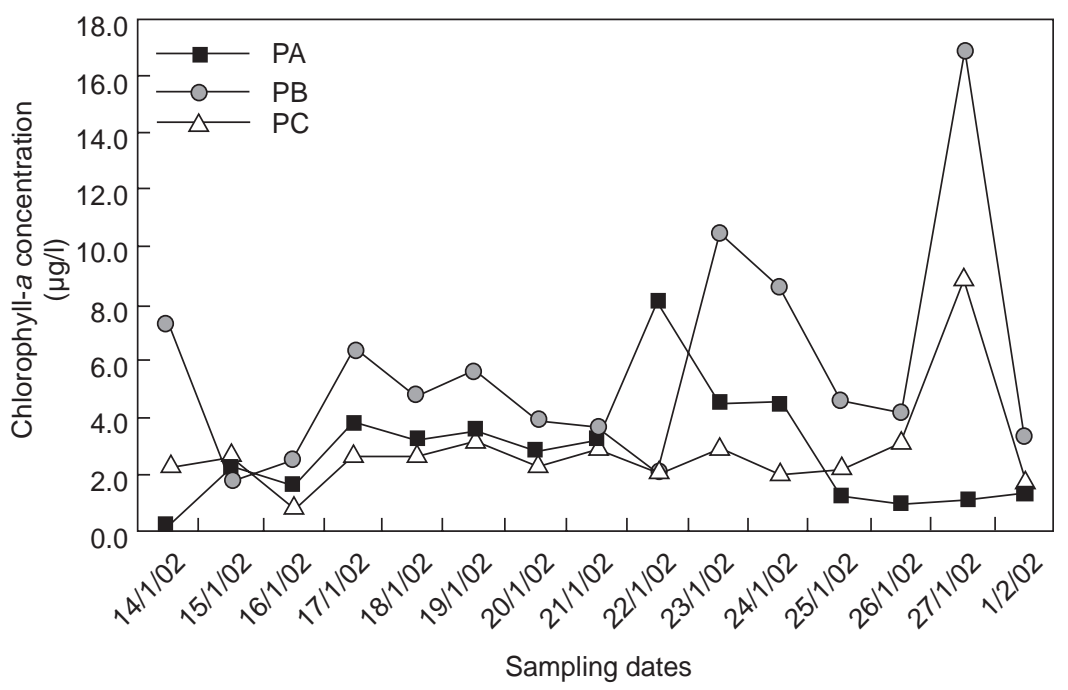

Fig. 3. Variation in chlorophyll- $a$ concentration during the second and third weeks of the time-series experiment. PA is the unfertilised pond, while $\mathrm{PB}$ and $\mathrm{PC}$ are the fertilised treatments 
algal mats. In the unfertilised pond, the maximum chlorophyll- $a$ concentration reached $7.96 \mu \mathrm{g} / \mathrm{l}$, implying that the ponds had some nutrients to support phytoplankton growth. The amount of chicken manure added (3 litres $/ 180 \mathrm{~m}^{2}$, every two days), equivalent to $83 \mathrm{~kg}$ dry matter/ha/day is higher than the standard amount of $50 \mathrm{~kg}$ dry matter/ha/ day, used at Station Dor, Israel (Milstein et al., $1991 ; 1995)$. Yet, this did not seem to have a great effect in terms of increased nutrients. Thus, it is not surprising that we did not observe significant differences between the control (Pond A) and the fertilised Pond C (post-hoc comparison of means, $\mathrm{P}=0.125)$. The presence of such an amount of phytoplankton in the water column (up to $7.96 \mu \mathrm{g} / \mathrm{l}$ chlorophyll-a) indicates that the food for zooplankton is always available, under natural conditions. Probably that is why immediately after flooding (and fertilisation in some cases) to initiate the hatching of resting eggs, one observes an increase in zooplankton numbers (Kyewalyanga et al., unpublished data). The availability of food makes growth and increase of zooplankton possible.

Similarly, we examined the dynamics of rotifers and protozoa in the earthen ponds over the same period. The commonly found rotifer was Brachionus plicatilis. This is known as an excellent food source for a variety of cultured organisms, including fish larvae (Lubzens, 1981; Schlüter \& Groeneweg, 1985). In Makoba ponds, we observed both these rotifers and unidentified protozoa (Fig. $4 \mathrm{a}$ and $\mathrm{b}$ ). On average, in the survey ponds the protozoa were significantly higher than rotifers in all the 3 ponds (ANOVA, followed by Post-hoc comparison of means (Tukey HSD); $\mathrm{P}=0.003$, 0.004 and 0.009 in $\mathrm{P} 1, \mathrm{P} 2$ and $\mathrm{P} 3$, respectively). However, ANOVA for fertilised ponds showed that there were no significant differences in the number of rotifers and protozoa within ponds $\mathrm{PA}, \mathrm{PB}$ and $\mathrm{PC}(\mathrm{P}>0.05)$. Tukey's HSD (Table 2) showed that while there was a significant difference in the number of rotifers between $\mathrm{PA}$ and $\mathrm{PB}(\mathrm{P}=0.019)$, there was none between PA and $\mathrm{PC}(\mathrm{P}=0.105)$ or between $\mathrm{PB}$ and $\mathrm{PC}(\mathrm{P}=0.752)$. In the survey ponds (using the same procedure) we found no significant difference in the number of rotifers or protozoa between $\mathrm{P} 1$ and $\mathrm{P} 2, \mathrm{P} 1$ and $\mathrm{P} 3$ or $\mathrm{P} 2$ and P3 (P values always > 0.05; see also Fig. 4a).

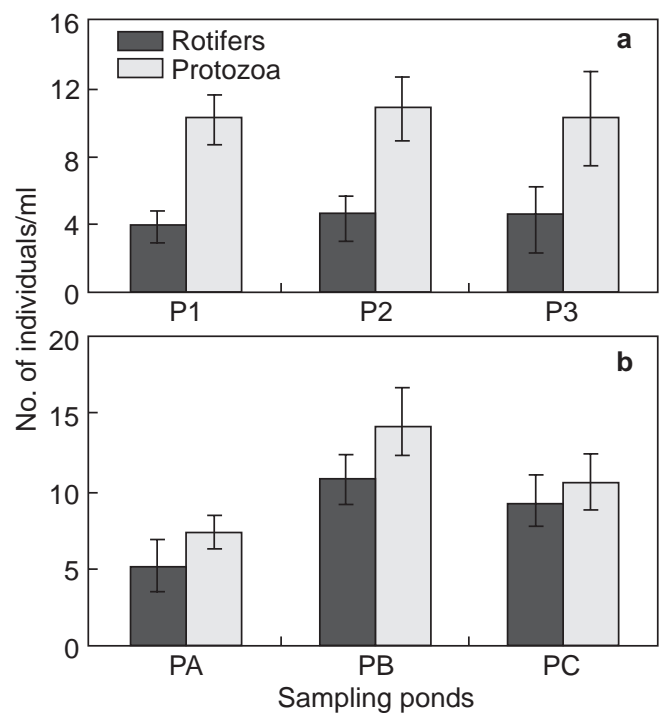

Fig. 4a. Average number of rotifers and protozoa sampled over the 10 months of survey in the four natural earthen ponds. Generally, protozoa were more abundant than rotifers in all the ponds. $4 \mathrm{~b}$. Average number of rotifers and protozoa sampled for 21 days (January 2002) during the time-series experiment in the control pond (PA) and in the fertilised ponds (PB and PC). Here also protozoa were slightly more abundant than rotifers.

The difference in the abundance between rotifers and protozoa (within ponds) was larger in the survey ponds compared with that in the fertilised ponds (as illustrated in Figs. 4a and b). Given the size of the ponds, the relatively low amount of fertilisers added (only 3 litres $/ 180 \mathrm{~m}^{2}$ ), environmental forces such as rainfall acting on the ponds, and the fact that flooding was done every 2-3 days to dilute the salinity, it is assumed that the final concentration of nutrients due to fertilisation in the ponds was low. If this assumption holds, then the dilution effect of rain and flooding of the ponds with reservoir water could have maintained the nutrients level closer to that of unfertilised ponds. Evidence could be seen during the time series experiment, in which the difference in the concentration of ammonia- $\mathrm{N}$ and soluble reactive phosphorus between fertilised and unfertilised ponds was not high, especially during the first two weeks of the experiments (see Figs 5 and 6). Thus, the results observed on the abundance of zooplankton suggest that in environments with low nutrients, protozoa thrive better than rotifers. 


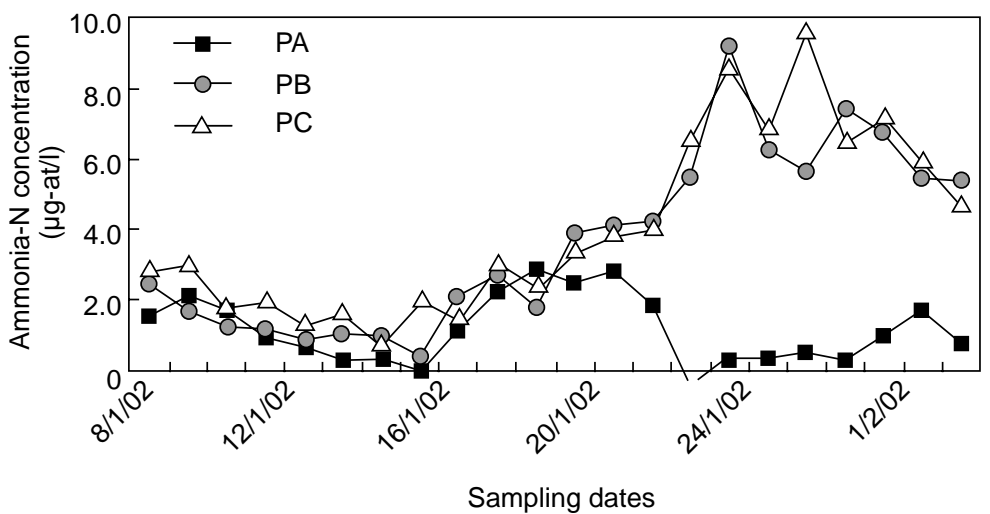

Fig. 5. Concentration of ammonia in earthen ponds during a 21-day time-series experiment. PA is the control, unfertilised pond, while $\mathrm{PB}$ and $\mathrm{PC}$ are fertilised ponds.

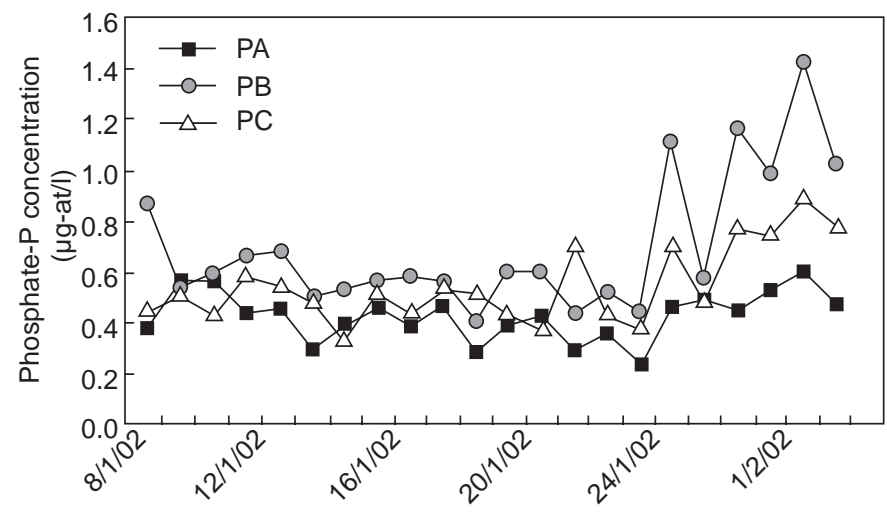

Sampling dates

Fig. 6. Concentration of soluble reactive phosphorus, determined daily in earthen ponds during the time-series experiment. PA is the control, unfertilised pond, while PB and PC are fertilised ponds.

Contrary to the observations on the dynamics of zooplankton in the ponds, the results of abundance of zooplankton in simulation containers showed that on average rotifers were most abundant in fertilised containers compared with protozoa. In fertilised containers $\mathrm{B}$ and $\mathrm{C}$, the maximum numbers of rotifer per $\mathrm{ml}$ were 75 and 60 respectively, while the maximum numbers of protozoa/ml in the same containers were only 20 and 15 , respectively (Fig. 7). The number of rotifers in fertilised containers was significantly higher than in the control, i.e., unfertilised and the reservoir (ANOVA at $\mathrm{P}<0.05$ ). Tukey's HSD test revealed significant differences between container $\mathrm{B} 1$ and the reservoir, $\mathrm{R}(\mathrm{P}=0.0001)$; between $\mathrm{C} 1$ and $\mathrm{R}(\mathrm{P}=0.0004)$; between $\mathrm{A} 1$ and $\mathrm{B} 1(\mathrm{P}=$ $0.0001)$ and between $\mathrm{A} 1$ and $\mathrm{C} 1(\mathrm{P}=0.002)$.

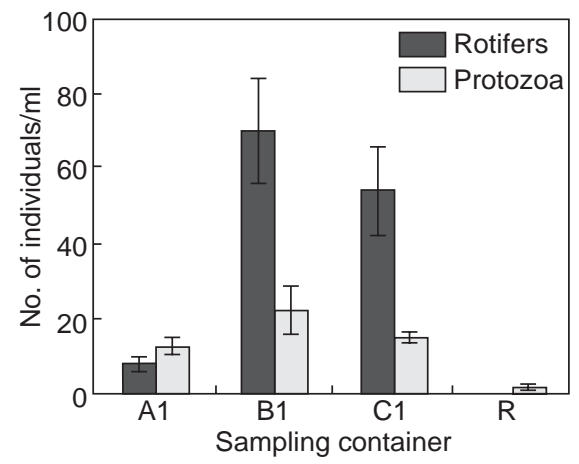

Fig. 7. Average number of rotifers and protozoa sampled for 21 days during the time-series experiment in January 2002. A1 is the control, unfertilised, container; $B 1$ and $C 1$ are fertilised containers; and $R$ is the reservoir. In the fertilised containers, rotifers were more abundant than protozoa, while in the controls the opposite was observed. 
However, B1 was not significantly different from $\mathrm{C} 1$ ( $\mathrm{P}=0.594$; Table 1). For the protozoa, between containers, a significant difference was observed only between $\mathrm{R}$ and $\mathrm{B} 1$ also between $\mathrm{R}$ and $\mathrm{C} 1$ ( $\mathrm{P}$ $=0.0004$ and $\mathrm{P}=0.041$, respectively). Comparing rotifers and protozoa, within the containers, the test revealed no significant difference in $\mathrm{A} 1$ or in the Reservoir $(\mathrm{P}=0.997)$. On the other hand rotifer numbers were significantly higher than protozoa within $\mathrm{B} 1(\mathrm{P}=0.0003)$ and within $\mathrm{C} 1(\mathrm{P}=0.004)$.

In the control/unfertilised container A, protozoa were more abundant than rotifers implying that rotifers prefer nutrient-rich environments. Because the containers were small and did not have much external forcing such as dilution by flooding or excessive rainfall, the accumulation of manure could have increased the nutrient concentrations. Even the comparison in the levels of ammonia-N (Fig. 8) and soluble reactive phosphorus (Fig. 9) between the control and the fertilised containers showed that the difference in the concentration was significantly high. The preference of rotifers to high nutrient concentration has also been observed elsewhere; for example, Fengqi (1996) observed abundant rotifers in waters with high eutrophication near villages and processing plants of aquatic or poultry products.

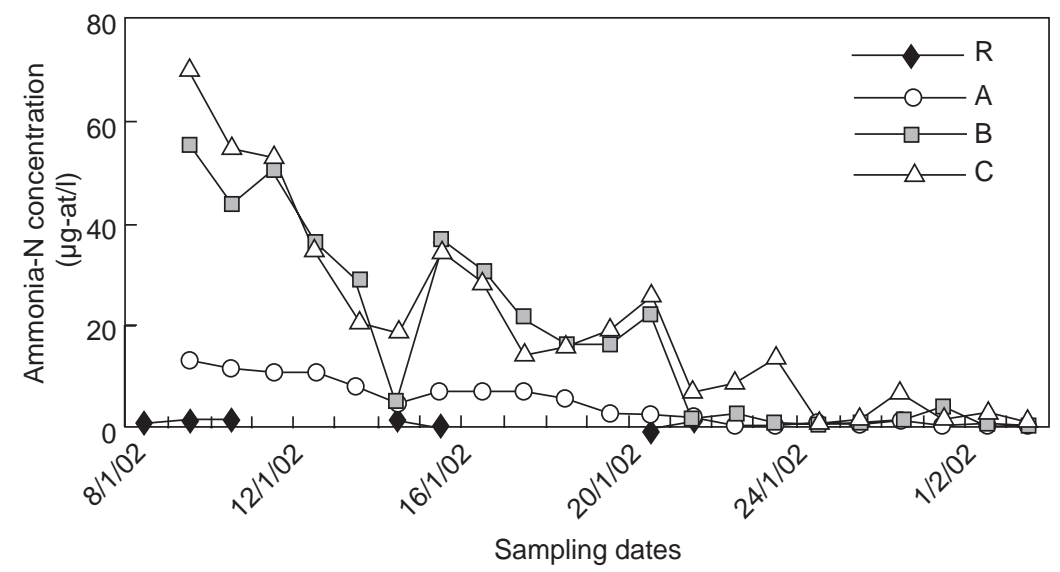

Fig. 8. Ammonia concentration determined daily for 21 days in simulation containers during the time-series experiment. $R$ is the reservoir; $A$ is the control/unfertilised container; while $B$ and $C$ are fertilised containers.

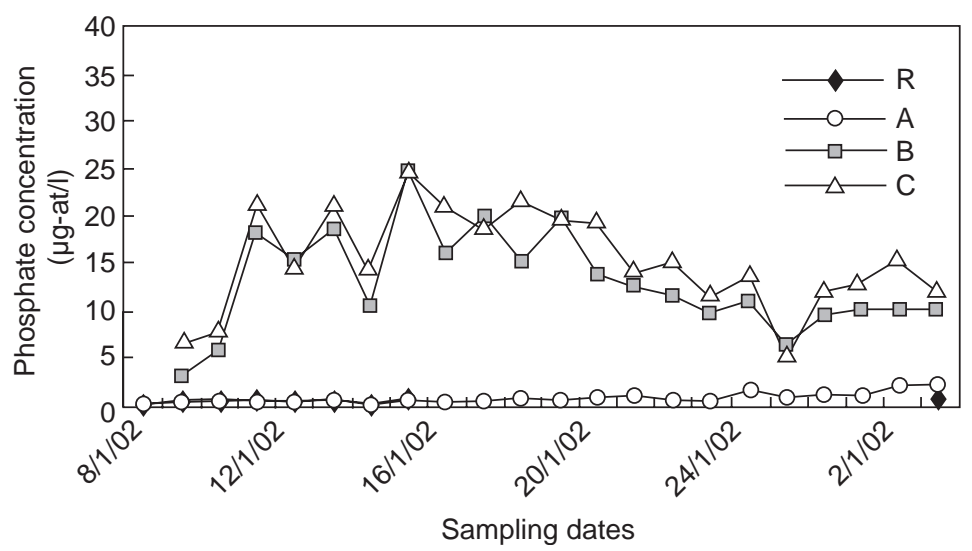

Fig. 9. Phosphorus concentration determined daily for 21 days in simulation containers during the time-series experiment. $\mathbf{R}$ is the reservoir; $A$ is the control/unfertilised container; while $B$ and $C$ are fertilised containers. 


\section{Short-term variation in live food}

A 21-day experiment was conducted to assess dayto-day variation in zooplankton and water-column phytoplankton in response to variations in environmental variables. Both pond and container experiments showed that the production of rotifers was slow in the first week of the experiment, started to increase rapidly in the second week, then peaked at the end of the second week. By the third week the abundance started to decline (Figs 10 and 11). This trend was observed both in fertilised and unfertilised ponds as well as in the fertilised containers, although in the containers protozoa did not increase significantly. In unfertilised containers and in the reservoir the number of rotifers remained low throughout the experimental period (Fig. 11). This suggests that regardless of the environment, the production of zooplankton, such as rotifers, copepods etc., in the ponds would reach a

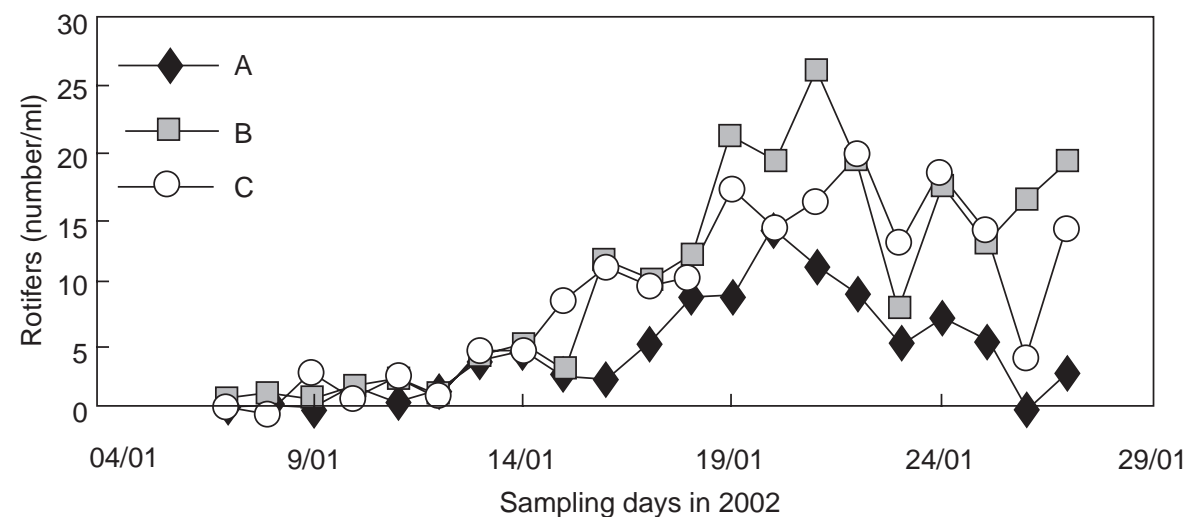

Fig. 10. Time-based variation in the number of rotifers /ml during the 21-day experiment (from 7 to 27 January 2002) conducted in earthen ponds in Makoba. $A$ is the control, unfertilised pond, $B$ and $C$ are the fertilised ponds.

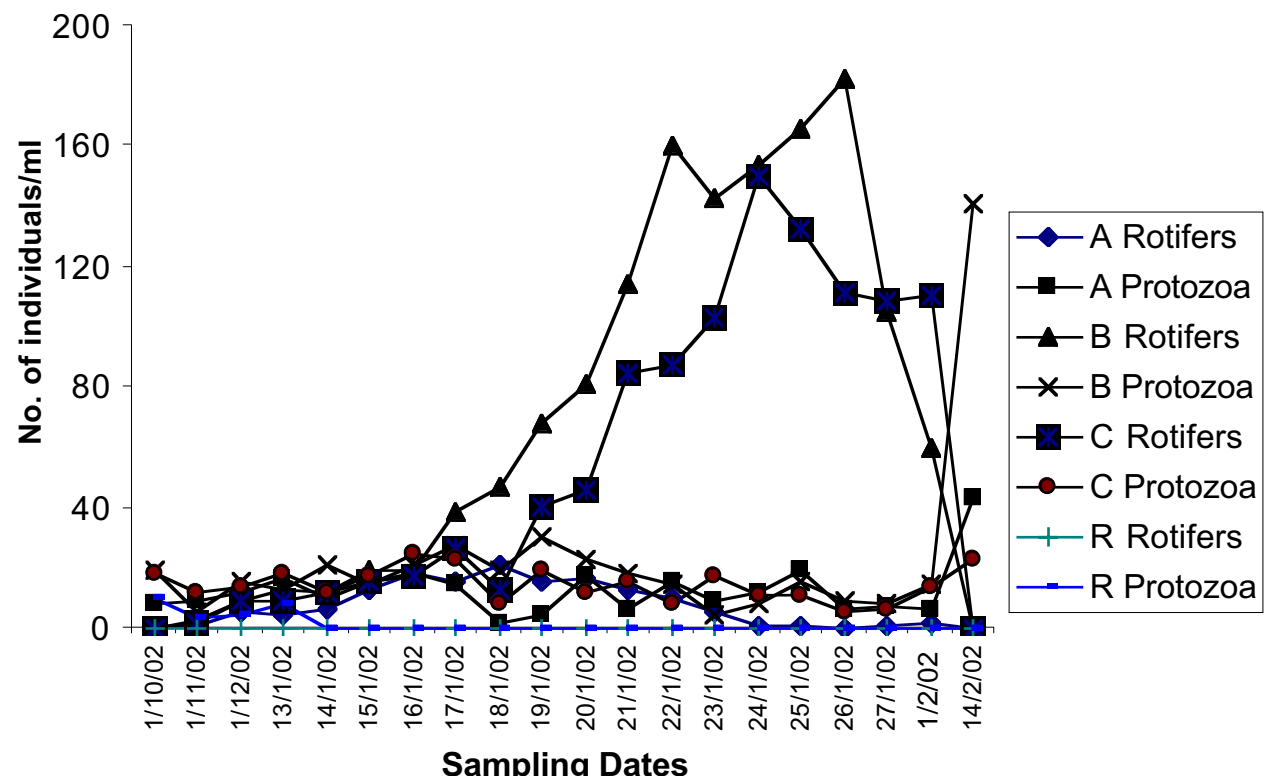

Fig. 11. Time-series variation in the number of rotifers and protozoa in simulation containers during a 21-day time series experiment (from 7 to 27 January 2002). pond $A$ and reservoir $R$ are unfertilised controls and $B$ and $C$ are fertilised ponds. Note that highest concentrations (number per $\mathrm{ml}$ ) of rotifers were observed in the fertilised ponds. 
maximum then decline (see also Harrell \& Bukowski, 1990). Similar results were also observed in previous studies conducted at the Makoba earthen ponds (Kyewalyanga et al., unpublished data; Kyewalyanga \& Mwandya, 2002). This probably happens when rotifers produce resting eggs (Dhert et al., 1995). Under certain conditions, rotifers produce resting eggs, which could remain dormant until when hatched after stimulation by some external conditions (Lubzens, 1981; Starkweather, 1987; Fengqi, 1996). Production of resting eggs can even be induced under laboratory conditions (Lubzens, 1981; Minkoff et al., 1983; Lubzens et al., 1993; Hagiwara et al., 1995; Dhert et al., 1995). The implication of this in the context of hatchery management is that one could not rely on a single live-food producing pond mesocosm or even initiate all the nursery ponds mesocosm at the same time. There should be a staggered system such that when zooplankton (specifically rotifers) in a pond(s) start to decline other ponds should have their stock at the initial or peaking stage. This would guarantee availability of enough live food for the fry/fingerlings being reared.

Nutrient concentrations (ammonia-N and soluble reactive phosphorus) in the experimental ponds did not decrease with increasing abundance of zooplankton and phytoplankton. They remained more-or-less constant in the first two weeks of the experiment, followed by a decrease in the third week, a trend similar to that of chlorophyll- $a$ concentration (compare Figs 3, 5 and 6). One would expect nutrient concentrations to decrease with increasing phytoplankton. However, here we observed the opposite. Probably the increase in phytoplankton standing stock was not significant enough to consume the available nutrients. The scenario in the fertilised containers was the opposite of what was observed for the ponds. The concentration of soluble reactive phosphorus stayed more-or-less constant, but on the high side and decreased slightly during the third week (Fig. 9), while ammonia was high in the first few days and progressively decreased with time (Fig. 8), most likely due to consumption by phytoplankton.

Unfortunately, no measurements of chlorophyll- $a$ were carried out in these fertilised containers, but zooplankton concentration showed progressive increase with time (Fig. 11), implying that they were getting enough food (phytoplankton). As previously discussed, when working with smaller containers it is easier to determine the effect of a given factor, unlike in the large area of the earthen pond that receives external influences, which could dilute the effect of the variable(s) to be determined.

Other measured environmental variables during the 10 months of survey-temperature, oxygen levels, water $\mathrm{pH}$ and conductivity (data not shown)-fluctuated with time. Nevertheless, seasonal changes, rainy vs. dry, could be discernible in these variables. For example, the water temperature was high during the dry season and low in the rainy season. Environmental variables such as salinity, temperature and nutrients as well as food availability are known to influence the formation and hatching of rotifer resting eggs (Lubzens, 1981; Minkoff et al., 1983), or the reproduction rates (Schluter \& Groeneweg, 1985). Detailed analysis of the variables and their effect, if any, will be reported elsewhere.

By comparing experimental results from natural earthen ponds with those from simulation containers, it was clearly seen that external forcing on natural ponds could significantly influence the outcomes. For example, the maximum numbers of rotifers $/ \mathrm{ml}$ in fertilised ponds B and C were 20 and 25 respectively (Fig. 10), while in the containers $\mathrm{B}$ and $\mathrm{C}$, the maximum reached 150 and 182 (Fig. 11) rotifers/ml, respectively. Similar effect was observed in the concentrations of nutrients, as discussed earlier (Figs 5 and 6 compared with 9 and 10). This observation could imply that the amount of fertiliser added in the ponds, 3 litres every two to three days, equivalent to $83 \mathrm{~kg}$ dry matter/ha/day, could have been on the low side for Makoba earthen ponds, at least during the rainy season. More trials need to be conducted to determine the optimal level of manure to be added, specifically in the natural ponds, to promote rotifer multiplication. The importance of this is based on the production of enough live food for feeding the hatched fry, when a hatchery is developed at Makoba. 


\section{CONCLUSION}

The study conducted in the earthen ponds at Makoba revealed the dominant phytoplankton and benthic algal genera that were found from November 2001 to August 2002 in the area. It further showed that protozoa would be present almost throughout the year, while rotifers would increase in abundance under favourable conditions of low-salinity fertile water. The survey is ongoing, and further data collection for another year or so, will give more information and better understanding of the types and abundance of both phytoplankton and zooplankton as well as their variability. It is possible that there could be interannual variations. The genus Spirulina seem to be an important component of the benthic food source for Makoba area (22\% composition). Further studies will look more closely at this genus, especially in the context of assessing optimal conditions for its growth and the possibilities of culturing it.

Rotifers are an excellent source of live food for fish fry, and the results from this study, as well as previous studies in the area, showed that rotifer resting eggs could be induced to hatch and produce in great numbers, given the right conditions. Therefore, once there is a reliable supply of freshwater at Makoba, it will be feasible to start a hatchery in which the fish larvae/fry could be reared in ponds, on live food.

Acknowledgements-I would like to thank Augustine Mwandya for his participation in several aspects of sampling, laboratory work and data processing, and Jasson Kyaruzi for helping with the collection and identification of phytobenthos as well as water-column phytoplankton, and A. Valdenberg for assisting in preparing the schematic diagram for Makoba site. The Administration at the Institute of Marine Sciences (IMS), Zanzibar, is acknowledged for providing some of the facilities. I am grateful for the constructive comments provided by an anonymous reviewer and one member of the Editorial Board, Prof. Y. Mgaya, which greatly improved the manuscript. The funding for carrying out this study was provided by Sida, through its Marine Science for Management (MASMA) grant to the Aquaculture Project of the IMS, for which I am very grateful.

\section{REFERENCES}

Bryceson, I. (1977) An ecological study of the phytoplankton of the coastal waters of Dar es Salaam. PhD thesis, University of Dar es Salaam, Tanzania. 165 pp.

Dhert, Ph., Schoeters, K., Vermeulen, P., Sun, J., Goa, S., Shang, Z. \& Sorgeloos, P. (1995) Production and evaluation of resting eggs of Brachionus plicatilis originating from the P.R. of China. In: Lavens, P., Japers, E. \& Roelants, I. (eds) Larvi'95 - Fish \& Shellfish Larviculture Symposium. European Aquaculture Society Special Publication Gent, Belgium, No. 24: 315-319.

Estudillo, C.B., Duray, M.N. \& Marasigan, E.T. (1998) Growth and survival of milkfish (Chanos chanos), seabass (Lates calcarifer) and rabbitfish (Siganus guttatus) larvae reared at the same density in different sized containers. The Israel J. Aquacult. - Bamidgeh 50: 20-24.

Fengqi, E. (1996) The use of rotifers in aquaculture. Aquaculture Magazine, May/June 1996: 16-22.

Hagiwara, A., Balompapueng, M.D. \& Hirayama, K. (1995) Mass production and preservation of marine rotifer resting eggs. In: Lavens, P., Japers, E. \& Roelants, I. (eds) Larvi'95 - Fish \& Shellfish Larviculture Symposium. European Aquaculture Society Special Publication Gent, Belgium, No. 24: 314.

Harrell, R.M. \& Bukowski, J. (1990) The culture, zooplankton dynamics and predator-prey interactions of Chesapeake Bay striped bass, Morone saxatilis (Walbaum), in estuarine ponds. Aquacult. Fisher. Manage. 21: 195-212.

Kyewalyanga, M. \& Mwandya, A. (2002) The effect of frequency of fertilisation on abundance of rotifers and protozoa in flooded ponds and simulation tanks. Western Indian Ocean J. Mar. Sci. 1: 11-18.

Lubzens E. (1981) Rotifer resting eggs and their application to marine aquaculture. In: Rosenthal, H. \& Oren, O.H. (eds) Research on intensive aquaculture, European Mariculture Society Special Publication No. 6, Bredene, Belgium, pp. 163-179.

Lubzens E., Wax Y., Minkoff G. \& Adler F. (1993) A model evaluating the contribution of environmental factors to the production of resting eggs in the rotifer Brachionus plicatilis. Hydrobiologia 255/256: 127-138.

Lugomela C. (1996) Studies of phytoplankton in the near shore waters of Zanzibar. MSc thesis, University of Dar es Salaam, Dar es Salaam, Tanzania. $174 \mathrm{pp}$.

Milstein, A., Alkon, A., Avnimelech, Y., Kochba, M., Hulata, G. \& Schroeder, G. (1991) Effect of 
manuring rate on ecology and fish performance in polyculture ponds. Aquaculture 96: 119-138.

Milstein, A., Alkon, A. \& Karplus, I. (1995) Combined effects of fertilisation rate, manuring and feed pellet application on fish performance and water quality in polyculture ponds. Aquaculture Research 26: 55-65.

Minkoff, G., Lubzens, E. \& Kahan, D. (1983) Environmental factors affecting hatching of rotifer (Brachionus plicatilis) resting eggs. Hydrobiologia 104: 61-69.

Parmley, D.C. \& Geiger, J.G. (1985) Succession patterns of zooplankton in fertilised culture ponds without fish. Progressive Fish-Culturist 47: 183186.
Parsons, R.P., Maita,Y. \& Lalli, C.M. (1984) A manual of chemical and biological methods for seawater analysis. Pergamon Press, N.Y. 173 pp.

Schlüter, M. \& Groeneweg, J. (1985) The inhibition by ammonia of population growth of the rotifer, Brachionus rubens, in continuous culture. Aquaculture 46: 215-220.

Starkweather, P.L. (1987) Rotifera. Animal Energetics 1: 159-179.

Sundström, B.G. (1986) The marine diatom genus Rhizosolenia. A new approach to the taxonomy. Doctoral Dissertation. Lund University, Lund, Sweden. $117 \mathrm{pp}$. 